\title{
Influência de temperaturas e de fotoperíodos na germinação in vitro de conídios de Aspergillus niger, agente etiológico do mofo preto da cebola
}

\author{
Leandro Luiz Marcuzzo ${ }^{1}$, Jessica Tainara $\operatorname{Ignaczuk}^{1}{ }^{\oplus}$
}

\begin{abstract}
${ }^{1}$ Instituto Federal Catarinense - IFC/Campus Rio do Sul, CP 441, 89.163-356, Rio do Sul, SC, Brasil.
Autor para correspondência: Leandro Luiz Marcuzzo (leandro.marcuzzo@ifc.edu.br)

Data de chegada: 17/09/2016. Aceito para publicação em: 10/02/2019.
\end{abstract}

$10.1590 / 0100-5405 / 169410$

A cebola (Allium cepa L.) é a terceira hortaliça mais cultivada e no Brasil, o estado de Santa Catarina contribuiu em 2017 com 29,6\% da produção nacional, totalizando 509.389 mil toneladas (1). Nesse estado, aproximadamente $80 \%$ desta produção concentra-se na região do Alto Vale do Itajaí, onde bulbos das cultivares Crioula e Bola Precoce são normalmente armazenados na propriedade, em estaleiros com ventilação natural, por um período de 60 a 120 dias, aguardando melhores preços para a comercialização. No entanto, o Instituto CEPA (2) estimou em 2013 perdas em torno de $27 \%$ da cebola armazenada nessas condições, perdas essas inaceitáveis para a maioria dos produtos agrícolas. Diversas doenças incidem sobre a cultura da cebola no armazenamento e entre elas o mofo preto também chamado de carvão do bulbo ou falso-carvão causado por Aspergillus niger van Tieghem tem sido comumente encontrado na pós-colheita da cultura. A doença é uma das principais causas da depreciação comercial dos bulbos no Brasil, no qual a cebola acaba sendo comercializada sem película, já que o patógeno deixa-as enegrecidas. A doença se manifesta em variedades que possuem película mais fina aliado ao processo inadequado de cura e de temperatura elevadas durante o armazenamento. Várias espécies de Aspergillus incidem sobre o bulbo de cebola, no entanto $A$. niger é o mais frequentemente encontrado em pós-colheita no Brasil. A. niger não possui hospedeiro especifico, podendo contaminar vários substratos ou causar doença em homens, animais e plantas e tem sido encontrado no solo, sobre matéria orgânica em decomposição e patogênico causando apodrecimento em frutas e hortaliças, podridão do hipocótilo do amendoim e podridão da haste de Dracena sp. (5). Os bulbos apresentam uma tonalidade de cores diferenciadas na película decorrente do desenvolvimento interno do patógeno, no entanto pode se desenvolver sobre a película em contato com outros bulbos infectados no armazenamento. A película externa solta e se rompe facilmente e quando ela é removida verifica-se uma fuligem preta constituídas pelos os esporos do fungo. Essa fuligem pode se desenvolver sobre a escama externa da cebola, mas não desenvolve internamente ao bulbo. $\mathrm{O}$ fungo não consegue penetrar diretamente na película mesmo quando há condições favoráveis de temperatura e umidade. A infecção ocorre pelo pescoço do bulbo nas cebolas inteiras ou através de ferimentos e/ou rompimento da película, e se desenvolvendo abaixo da película externa. O patógeno cresce com intensidade ao longo das nervuras das escamas. A variação de temperatura no armazenamento favorece a infecção, no entanto esse processo não tem sido descrito com detalhes. O conhecimento da biologia do patógeno é de grande importância para compreender o desenvolvimento da doença, bem como para tomar medidas de manejo da doença. Diante disto, este trabalho teve como objetivo avaliar em condições in vitro a influência da temperatura e do fotoperíodo na germinação de conídios de $A$. niger. A pesquisa foi realizada no Laboratório de Microbiologia e Fitopatologia do Instituto Federal
Catarinense/Campus Rio do Sul com isolado identificado de $A$. niger, obtido de bulbo de cebola com sintoma da doença e multiplicado em placas de Petri contendo meio de cultura em BDA (batata-dextrose-ágar) através da coleta de conídios sobre o bulbo. Posteriormente as placas foram incubadas em câmaras de germinação do tipo Biological Oxigen Demand (B.O.D) a $25^{\circ} \mathrm{C}$ e fotoperíodo de 12 horas durante o período de sete dias. Após isso os conídios foram removidos através de raspagem com pincel e água esterilizada e distribuídos com auxílio de alça de Drigalski $100 \mu 1$ de suspensão de conídios contendo a concentração de $8 \times 10^{4}$ conídios $/ \mathrm{mL}$ em cinco (repetições) placas de Petri com meio ágar-água $1 \%$. Em seguida, as placas foram incubadas a temperaturas de $10,20,30,40,50$ e $60^{\circ} \mathrm{C}$ em escuro contínuo. Em um segundo momento repetiu-se o experimento incubando conídios de $A$. niger a $34^{\circ} \mathrm{C}$ (temperatura ideal de germinação obtida com o experimento da temperatura) com os fotoperíodos de 0, 6, 12, 18 e 24 horas de luz. Em ambos os experimentos foi avaliada a percentagem de germinação após 24 horas de incubação. Devido ocorrer baixa germinação ( $20 \%$ na temperatura de $30^{\circ} \mathrm{C}$ ) em ágar-água $1 \%$, foi realizado um experimento contendo três repetições com adição de100 $\mu 1$ de suspensão em água destilada estéril de $0,1,5,10$ e $50 \%$ de cebola picada $(0,5 \times 0,5 \mathrm{~cm})$ agitadas por 15 minutos na superfície do meio e espalhadas com a alça de Drigalski e em seguida a suspensão de conídios. Para visualização dos conídios em ambos os experimentos foi adicionado algumas gotas de azul de metileno 0,33\% e com movimentos circulares espalhou-se o corante sobre toda a superfície com o corante. A contagem foi feita com microscópio óptico com magnitude de 100 vezes através da contagem de 100 conídios aleatórios na placa. Foi considerado germinado o que apresentou o tubo germinativo maior que o diâmetro do conídio. Os dados foram submetidos à análise estatística. Verificouse que a aplicação da suspensão de cebola aumentou de $21,3 \%$ para 38,$3 ; 59,7 ; 90$ e $91 \%$ respectivamente nas suspensões de $0,1,5,10$ e $50 \%$. Não houve diferença estatística (Tukey 5\%) entre a suspensão de 10 e $50 \%$ e a germinação foi representada pela equação $y=-$ $0,128 x^{2}+7,736 x+25,43\left(R^{2}=0,987\right)$. Devido a esse resultado foi utilizado à suspensão de $10 \%$ para avaliar o efeito da temperatura e fotoperíodo. Essa informação explica porque não ocorreu esporulação nas túnicas e escamas de cebola que não tinham ferimento no trabalho de Marques (Efeito da temperatura e do fotoperíodo no desenvolvimento in vitro e in vivo de Aspergillus niger em cebola. 2015. 44p. Trabalho de curso. Instituto Federal Catarinense, campus Rio do Sul, Rio do Sul) e também por Thamizharasi \& Narasimham (4), em que bulbos não foram infectados quando estavam intactos, mas o fungo invadia rapidamente os bulbos feridos. Isso evidencia que necessita exsudação dos compostos celulares da cebola para que ocorra a infecção e conseqüente esporulação dos conídios em sua superfície. Com base nos dados obtidos, constatou-se que a temperatura exerce grande influência sobre a germinação dos conídios de $A$. niger. Devido ao baixo ajuste da curva 

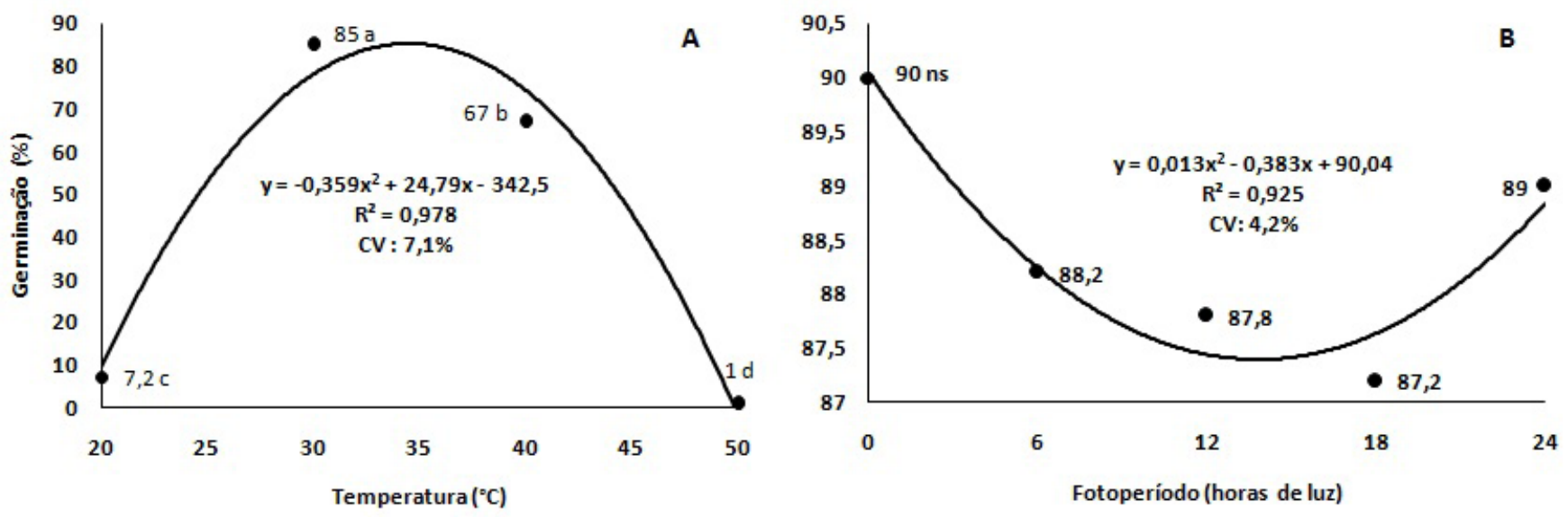

Figura 1. Curva de germinação de conídios de Aspergilus niger sob diferentes temperaturas (A) e fotoperíodos (B). IFC/Campus Rio do Sul, 2016.

$\left(\mathrm{R}^{2}=0,594\right)$ entre 10 e $60^{\circ}$, já que apresentaram 1,2 e $0,8 \%$ respectivamente de germinação e que não diferiram entre si (Tukey $5 \%$ ) foram excluídas do experimento. Essas duas temperaturas também não diferiram entre si de $50^{\circ} \mathrm{C}$. Observa-se que entre as temperaturas de 30 e $40^{\circ} \mathrm{C}$ (Figura 1A) houve a maior percentagem de germinação variando ente 85 e $67 \%$ respectivamente. Isso, provavelmente, reflete o que ocorre no campo, pois a temperatura ótima para o desenvolvimento do mofo preto varia entre 28 e $34^{\circ} \mathrm{C}$. A germinação dos conídios também foi bruscamente reduzida nas temperaturas de 20 e $50^{\circ} \mathrm{C}$ sendo de $7,2 \%$ e $1 \%$ respectivamente. Wordell filho et al. (5) descreve que temperatura de $50^{\circ} \mathrm{C}$ por 3 horas (máximo tolerado pela cebola) resultou na morte de $18 \%, 58 \%$ e $100 \%$, respectivamente, dos esporos secos, úmidos e germinados de A. niger. Em meio de cultura, o fungo cresce à temperatura mínima de $17^{\circ} \mathrm{C}$, da mesma forma que a germinação dos conídios nos tecidos dos bulbos danificados como ao encontrado em $20^{\circ} \mathrm{C}$ e $1,2 \%$ a $10^{\circ} \mathrm{C}$ nesse trabalho. Pelos dados obtidos observa-se que na temperatura de $20^{\circ} \mathrm{C}$ a percentagem de germinação foi de 7,2 $\%$, sendo $91,52 \%$ inferior a germinação a $30^{\circ} \mathrm{C}$, concordando com o descrito por Maude (3). Esses resultados in vivo confirmam os obtidos com esse trabalho in vitro. Constatou-se que $A$. niger tem sua germinação favorecida em temperaturas entorno dos $34^{\circ} \mathrm{C}$ e isto acontece durante o armazenamento da cebola na região do Alto Vale do Itajaí/SC, favorecendo a germinação dos conídios e consequentemente a ocorrência da doença. Na Figura 1B observa-se a influência do fotoperíodo na germinação de conídios de A. niger, onde nos fotoperíodos de $0,6,12,18$ e 24 horas, obteve-se respectivamente 90; 88,$2 ; 87,8 ; 87,2$ e $89 \%$ de germinação. Ressaltando que o fotoperíodo exerce pouca influência na germinação de conídios, diferindo-se apenas $3,1 \%$ do maior para o menor percentual de geminação, mas não significativo (Teste F) entre os fotoperíodos. Em decorrência disso é possível que $A$. niger tem seu desenvolvimento favorecido por temperaturas elevadas $\left(34^{\circ} \mathrm{C}\right)$ e menores períodos de luz, assim levando a crer que esta característica do fungo vem torná-lo mais agressivo no armazenamento de cebola a granel ou em sacos empilhados em galpões mal ventilados que acabem aumentando a temperatura e aonde não recebe iluminação, como o que acontece na região do Alto Vale do Itajaí durante o armazenamento da cebola. Conclui-se que a germinação de $A$. niger sofre influência da temperatura e nenhuma do fotoperíodo, onde os maiores valores de crescimento são obtidos em temperaturas de 30 a $40^{\circ} \mathrm{C}$, sendo a temperatura ótima de $34^{\circ} \mathrm{C}$ e no escuro, onde deve-se evitar essas condições durante o armazenamento de bulbos de cebola. As informações obtidas em relação à temperatura e o fotoperíodo na germinação de conídios de $A$. niger permitem um maior conhecimento da biologia do agente causal do mofo preto cebola, auxiliando no entendimento da epidemiologia e suporte para manejo da doença no armazenamento.

\section{REFERÊNCIAS}

1. IBGE. Levantamento sistemático da produção agrícola: pesquisa mensal de previsão e acompanhamento das safras agrícolas no ano civil, dezembro 2017. Rio de Janeiro, 2018 Disponível em: $<$ https://biblioteca.ibge.gov. br/index.php/biblioteca-catalogo? view $=$ detalhes \&id=76>.Acessoem: 09 jul. 2018.

2. ICEPA. Instituto de Planejamento e Economia Agrícola de Santa Catarina/ EPAGRI. Dados e Informações - Balanço de oferta e demanda - safras 2012/13. Florianópolis: Epagri/Cepa. Disponível em <http://www.epagri. sc.gov.br/?page_id=2620>.Acesso em: 22 ago. 2016.

3. Maude R.B. Storage diseases of onions. In: Rabinowitch, H.D.R.; Brewster, J.L. (Eds.). Onions and allied crops: agronomy, biotic interactions, pathology, and crop protection. Flórida: CRC Press. p.273-296, 1990.

4. Thamizharasi, V.; Narasimham, P. Growth of Aspergillus niger on onion bulbos and its control by heat and sulphur dioxide treatments. Tropical Science, v.33, n.1, p.45-55, 1992.

5. Wordell Filho, J. A.; Boff, P. Carvão-do-bulbo ou falso-carvão-Aspergillus spp. Walker. In: Wordell Filho, J.A.; Rowe, E.; Gonçalves, P.A.; Debarba, J.F.; Boff, P.; Thomazelli, L.F.. Manejo Fitossanitário na cultura da cebola. Florianópolis: EPAGRI, p.110-116, 2006. 